\title{
Electroencephalogram abnormalities in panic disorder patients: a study of symptom characteristics and pathology
}

\author{
Karin Hayashi ${ }^{*}$, Mariko Makino ${ }^{2}$, Masahiro Hashizume ${ }^{2}$, Koichi Nakano $^{3}$, Koji Tsuboi $^{2}$
}

\begin{abstract}
Background: Since the 1980s, a high EEG abnormality rate has been reported for patients with panic disorder. However, how the EEG abnormalities of panic disorder patients are related to the clinical features and pathology of these patients has yet to be clarified. In this study we investigated whether or not EEG abnormalities are related to the 13 symptoms in the DSM-IV criteria for a diagnosis of panic attacks.

Methods: Subjects were 70 patients diagnosed with panic disorder.

Logistic regression analysis was performed with EEG findings as dependent variables and age, sex and with or without the 13 symptoms as independent variables.

Results: (1)EEG findings for panic disorder patients with EEG abnormalities: Of the 17 patients, 13 had repeated slow waves in the $\theta$-band; the most prevalent EEG abnormality found in this study. Paroxysmal abnormality interpreted as epileptiform was found in only two cases. (2)Nausea or abdominal distress (37.7\% vs 82.45\%, OR-12.5), derealization or depersonalization (7.5\% vs $47.1 \%, \mathrm{OR}=13.9$, ) and paresthesias $(43.4 \%$ vs $64.7 \%, \mathrm{OR}=7.9$, ) were extracted by multivariate analysis as factors related to EEG abnormalities.

Conclusion: Of the 70 patients studied, 17 had EEG abnormalities. Among these 17 cases, "repeated slow waves in the $\theta$-band" was the most common abnormality. The factors identified as being related to EEG abnormalities are nausea or abdominal distress, derealization or depersonalization, and paresthesias. The study indicated that physiological predispositions are closely related to panic attacks.
\end{abstract}

\section{Background}

Recently, panic disorder causing panic attacks characterized by symptoms including unexpected palpitation, dyspnea, dizziness, and paresthesias has increasingly been consulted in various kinds of clinics and hospitals. Katon and colleagues reconfirmed that $6.7 \%$ of primary care patients meet the diagnostic criteria for panic disorder (PD) [1]. It is also reported that $28 \%$ of PD patients consult emergency rooms (ER) [2]. The lifetime prevalence of PD is $0.4 \%$ in Taiwan [3]. According to National Comorbidity Survey (NCS) data, the life prevalence of PD in the United States is 3.5\% while the life prevalence of panic attack (PA) is 7.3\% [4]. In Japan, Kaiya reported that out of 4,000 subjects investigated, the prevalence

\footnotetext{
* Correspondence: karin@med.toho-u.ac.jp

'Department of Neuropsychiatry, Sakura Medical Center, Faculty of Medicine, Toho University, Chiba, Japan

Full list of author information is available at the end of the article
}

among subjects whose response met the criteria for PA was $6.6 \%$ while the prevalence among those whose response met the criteria for PD was 5.0\%[5].

The initial manifestation age of panic disorder is in one's twenties and the risk in women is twice as high as in men [6]. In panic disorder, anticipatory anxiety and agoraphobia continue even between panic attacks and patients can be operationally diagnosed as having panic disorder from clinical symptoms. However, PD has another aspect that has been understood as a brain problem rather than a mental problem because it is induced when the sodium lactate level increases. Recent studies on PD in brain science suggest that some pathologic brain conditions such as lesions in the amygdala and hippocampus are deeply related to the disorder and other reports hold the coincident view that blood flow decrease in the prefrontal cortex is involved [7-10].

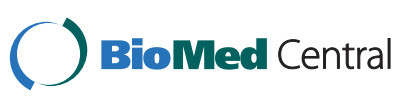

() 2010 Hayashi et al; licensee BioMed Central Ltd. This is an Open Access article distributed under the terms of the Creative Commons Attribution License (http://creativecommons.org/licenses/by/2.0), which permits unrestricted use, distribution, and reproduction in any medium, provided the original work is properly cited. 
Furthermore, according to genetic studies, the hereditability of panic disorder is in the range of $35-40 \%$ with concordance in identical twins being higher than that in fraternal twins. However, many studies report concordance in identical twins to be $50 \%$ or less. The above suggest that both genetic disposition and environmental factors are related to panic disorder [11-13].

Since the 1980s, a high EEG abnormality (15-30\%) has been reported for patients with PD [14-17]. We carried out this study to investigate how the EEG abnormalities of PD patients are related to the clinical features and pathology of these patients. The risk of diagnosing panic disorder as epilepsy has been pointed out by some specialists. There are a few case studies in which patients who had been initially diagnosed with panic disorder later proved to have been suffering from epilepsy[18,19]. This misdiagnosis risk could be attributed to the fact that of the 13 symptoms in the diagnosis criteria of panic attack in the Diagnostic and Statistical Manual of Mental Disorders(DSM)-IV, 12 symptoms are also observed in partial epilepsy[20,21]. Feeling of chocking is the only exception. It should be noted that epilepsy is diagnosed operationally, while an EEG check is only supplementary.

We have studied PD which shows EEG abnormalities, and found that some of the EEG abnormalities were related to PD. Some other subjects of our study had a significantly higher rate of "hypersensitivity to strong lights or flashes" and "conversions anamnesis" than patients without EEG abnormalities.

The objective of this study is to investigate whether or not EEG abnormalities are related to the 13 symptoms in the DSM-IV criteria for a diagnosis of panic attacks and to consider how panic disorder and EEG abnormalities relate to each other.

\section{Methods}

\section{[Subjects]}

The Subjects consisted of 903 males (age $40.7 \pm 16.6$ ) and 1,416 females (age 41.1 \pm 18.5 ) who visited for the first time the Department of Psychosomatics Medicine at Toho University Omori Medical Center in the period from February 2007 to July 2008. First, subjects were examined by interview doctors to confirm that they had the 13 symptoms used in the diagnosis criteria of panic attack in DSM-IV. Second, psychosomatic medicine specialists excluded physical diseases such as arrhythmia, angina, hyperthyroidism, chronic obstructive pulmonary disease (COPD), asthma, pheochromocytoma, and neurological disorders, including evident epilepsy. Subjects were informed of the medical significance $[22,23]$ of EEG for all patients diagnosed with panic disorder. Finally, 115 subjects between the ages of 18-65 who gave consent to EEG check were selected. The list was further shortened to 70 subjects (20 males, age $33.2 \pm$ 8.2 and 50 females, age $35.0 \pm 9.5$ ) when the following groups were excluded:

1) Patients who regularly take psychotropic drugs and other medicines with EEG effects 2) Patients with schizophrenia, severe depression, and personality disorders

3) Patients with alcoholism or drug abuse

4) Patients with severe complications of circulatory, respiratory, digestive, endocrine and neurological disease.

The selected 70 subjects were made aware of the purpose and methods of the study. They were assured that study data would be anonymously and statistically treated. It was also made clear that personal data would not be disclosed to anyone including administrative authority. Questions from subjects were readily answered and subjects were given the choice to decline to participate in the study without fearing any consequences.

The Ethics Committee of Faculty of Medicine Toho University approved this study. They also approved EEG check of panic disorder patients within normal medical examination procedures. Furthermore, to avoid delay in the commencement of treatment, EEG technicians were advised to check patients EEG on the first examination day.

\section{[EEG record]}

For EEG record, Nihon Kohden EEG-1514 leads were attached to both earlobes (A1 and A2). The reference electrode was 12 channels: Fp1, Fp2, C3, C4, P3, P4, 01, 02, F7, F8, T3 and T4, according to the international 10-20 system of Electrode Placement, and the EEG was recorded for 15 consecutive minutes or more. The bipolar leads were 12 channels: Fp1-F3, Fp2-F4, F3-C3, F4C4, C3-P3, C4-P4, P3-01, P4-02, Fp1-F7, Fp2-F8, F7-T3 and F8-T4, and the EEG was recorded for 2 consecutive minutes or more. Photic stimulation was given at 10 second intervals at $3,5,6,8,10,12,14,15,18,20$ and $24 \mathrm{~Hz}$, and hyperventilation was carried out for $5 \mathrm{~min}$ utes at 3 second intervals. The time constant was 0.3 seconds by high cut filter $120 \mathrm{~Hz}$ and the contact resistance was $10 \mathrm{k} \Omega$ or less.

\section{[EEG record reading and interpretation]}

EEG record reading was based on the decision criteria of adult EEG proposed by Teruo Ohkuma in 1999, which are widely accepted in Japan. The criteria details are 1) EEG with eyes closed is composed of $\alpha$ wave or faster activity than $\alpha$ wave. Obvious $\theta$ and $\delta$ waves do not appear. 2) $\alpha$ waves and fast activity show normal localization. 3) There is no difference of $20-30 \%$ or more in the amplitude of symmetric parts. 4) There is no difference of $10 \%$ or more in the duration of symmetric parts. 5) $\alpha$ attenuation occurs with open eyes, 
sensory stimuli, and mental activities et cetera. 6) Neither $\alpha$ wave nor fast activity show abnormally high amplitude. 7) No intermittent activities appear, such as spike waves or sharp waves(intermittent abnormal activity, epileptic pattern.

We used the criteria and the author read all EEG records of patients before contact with them. The peculiar EEG patterns which are difficult to read or with clinical significance unknown at present (not taken as abnormal findings in reading EEG), such as 14 \& $6 \mathrm{~Hz}$ positive spike, small sharp spikes, $6 \mathrm{~Hz}$ spike and slow waves, psychomotor variant, SREDA (subclinical rhythmic electroencephalographic discharge of adults) and Wicket spikes were considered normal as long as they were not frequent and their basic activity's localization, rhythmicity and consecutiveness were stable [24,25]. The interpretation of the EEGs was finalized after double-checking by my executive doctor.

\section{[Statistical analyses]}

Logistic regression analysis was performed with EEG findings as dependent variables and with or without the 13 symptoms above, age and sex were independent variables.

We confirmed there was no significant difference with agoraphobia, psychiatric disorders, drinker, and smoker or not (Table 1). The independent variables were selected stepwise and by forward selection under the likelihood ratio testing was selected. The SPSS version 13 was used for statistical analysis.

\section{Results}

(1) EEG findings of panic disorder patients with EEG abnormalities (see Table 2)

The most prevalent EEG abnormalities were slow waves bursts temporally repeated, found in 11 of 17 cases (representative EEG waves in Figures 1). There was no localization. Some of them had no difference between right and left, however 4 cases were dominant in the right side.
Paroxysmal abnormality interpreted as epileptiform was found only in 2 cases: No. 5 (Figure 2) and No. 16. The positive spike waves in No. 12 and the positive sharp waves in No. 14 were interpreted as abnormal because they had a difference between right and left side and were repeating in the same region. No slow wave complex was found and amplitudes were low or medium, therefore they were not considered as epileptiform discharges. In 8 of the 17 cases, an evident build up was found by hyperventilation, although all patients recovered in 30 seconds.

(2) The 13 symptoms in the DSM-IV diagnosis criteria and EEG findings (see Table 3)

Nausea or abdominal distress $(37.7 \%$ vs $82.45 \%$, OR = 12.489, 95\%CI: 2.422-64.426, $\mathrm{p}=0.003$ ); derealization (feelings of unreality) or depersonalization (being detached from oneself) ( $7.5 \%$ vs $47.1 \%$, OR $=13.919$, 95\%CI: 2.579-75.083, $\mathrm{p}=0.002$ ); or paresthesias (numbness or tingling sensations) $(43.4 \%$ vs $64.7 \%$, OR = 7.928, 95\%CI: $1.567-40.082, \mathrm{p}=0.012$ ) were extracted by multivariate analysis as factors related to EEG abnormalities (Table 4).

\section{Discussions}

[EEG abnormality rate in PD patients]

In the 1990s, it was often said that many panic disorder patients had abnormal EEG[15-17]. On the other hand, Stein et al could not find many EEG abnormalities in their patients with PD (14.3\%). This was a descriptive epidemiological study. In their study, however, the number of cases was 35, which is considered small. Moreover, all EEGs were read by the neurologists who were directly examining the patients, which may have caused their decision criteria to be varied or their conclusions to be biased [14].

The study of Lepola et al. was part of a larger trial studying "the effect of psychotropic medication on panic disorder". It was a descriptive epidemiological study in which 54 consecutive inpatients were included. The aim of the study was to investigate the EEGs of a large

Table 1 Characteristics of patients with panic disorder subclassified on the basis of EEG findings

\begin{tabular}{lll}
\hline & EEG normal(M/F) & EEG abnormal(M/F) \\
\hline Panic Disorder & $53(17 / 36)$ & $17(3 / 14)$ \\
With agoraphobia & $33(11 / 22)$ & $14(3 / 11)$ \\
With other recent psychiatric disorders & & $2(0 / 2)$ \\
$\quad$ Depression & $6(3 / 3)$ & $1(0 / 1)$ \\
$\quad$ Somatoform disorder & $2(0 / 2)$ & \\
With other past psychiatric disorders & & $4(1 / 3)$ \\
Depression & $7(2 / 5)$ & 0 \\
Somatoform disorder & 0 & $3(0 / 3)$ \\
Smoker & $22(8 / 14)$ & $2(2 / 0)$ \\
Drinker & $9(5 / 4)$ & \\
\hline
\end{tabular}


Table 2 EEG abnormal findings of 17 cases

\begin{tabular}{|c|c|c|c|c|c|c|}
\hline No. & age & sex & Basic activity & Abnormal findings & Focus & Build up \\
\hline 1 & 26 & female & 9-10 Hz irregular & Slow wave burst $(\theta \delta)$ & PO diffuse & + \\
\hline 2 & 59 & female & 10-12 Hz irregular & Slow wave burst $(\theta)$ & $\mathrm{CPO}$ & Cannot check \\
\hline 3 & 40 & female & $10 \mathrm{~Hz}$ regular & Slow wave burst $(\theta)$ & Right CPO & - \\
\hline 4 & 26 & female & $9 \mathrm{~Hz}$ regular & Slow wave burst $(\theta)$ & Diffuse & - \\
\hline 5 & 18 & female & 10-11 Hz regular & Sharp \& slow wave complex *1 & Right & - \\
\hline 6 & 33 & female & 10-11 Hz regular & Slow wave burst $(\theta)$ & $\mathrm{CPO}$ & - \\
\hline 7 & 36 & female & 10-11 Hz regular & Slow wave burst $(\theta)$ & $\mathrm{CPO}$ & - \\
\hline 8 & 35 & female & $9 \mathrm{~Hz}$ irregular & Slow wave burst $(\theta)$ & $\mathrm{CPO}$ & - \\
\hline 9 & 37 & female & 10-12 Hz regular & Slow wave burst $(\theta)$ & Diffuse & - \\
\hline 10 & 23 & female & 9-11 Hz regular & Sharp wave (6 hz) & $\mathrm{CPO}$ & + \\
\hline 11 & 31 & male & $12 \mathrm{~Hz}$ regular & Slow wave burst ${ }^{*} 2$ & PC & + \\
\hline 12 & 35 & male & 8-10 Hz irregular & $\begin{array}{l}\text { Slow wave burst }(\theta) \\
\text { Positive spike waves }\end{array}$ & $\begin{array}{l}\text { Diffuse } \\
\text { Right Fp }\end{array}$ & + \\
\hline 13 & 34 & female & 8-10 Hz irregular & Slow waves (7 hz) & intermingled at basic activity & - \\
\hline 14 & 38 & female & 10-11 Hz regular & Positive sharp waves & Left CPO & + \\
\hline 15 & 39 & male & $10 \mathrm{~Hz}$ regular & Slow waves (6-7 hz) & intermingled at basic activity & + \\
\hline 16 & 47 & female & 10-11 Hz regular & spike \& slow wave complex & Right & + \\
\hline 17 & 19 & female & 10-12 Hz irregular & Slow wave bursts (6-7 hz) & Diffuse & + \\
\hline
\end{tabular}

*1) the EEG waves of this case were shown in Figure 2

*2) the EEG waves of this case were shown in Figure 1

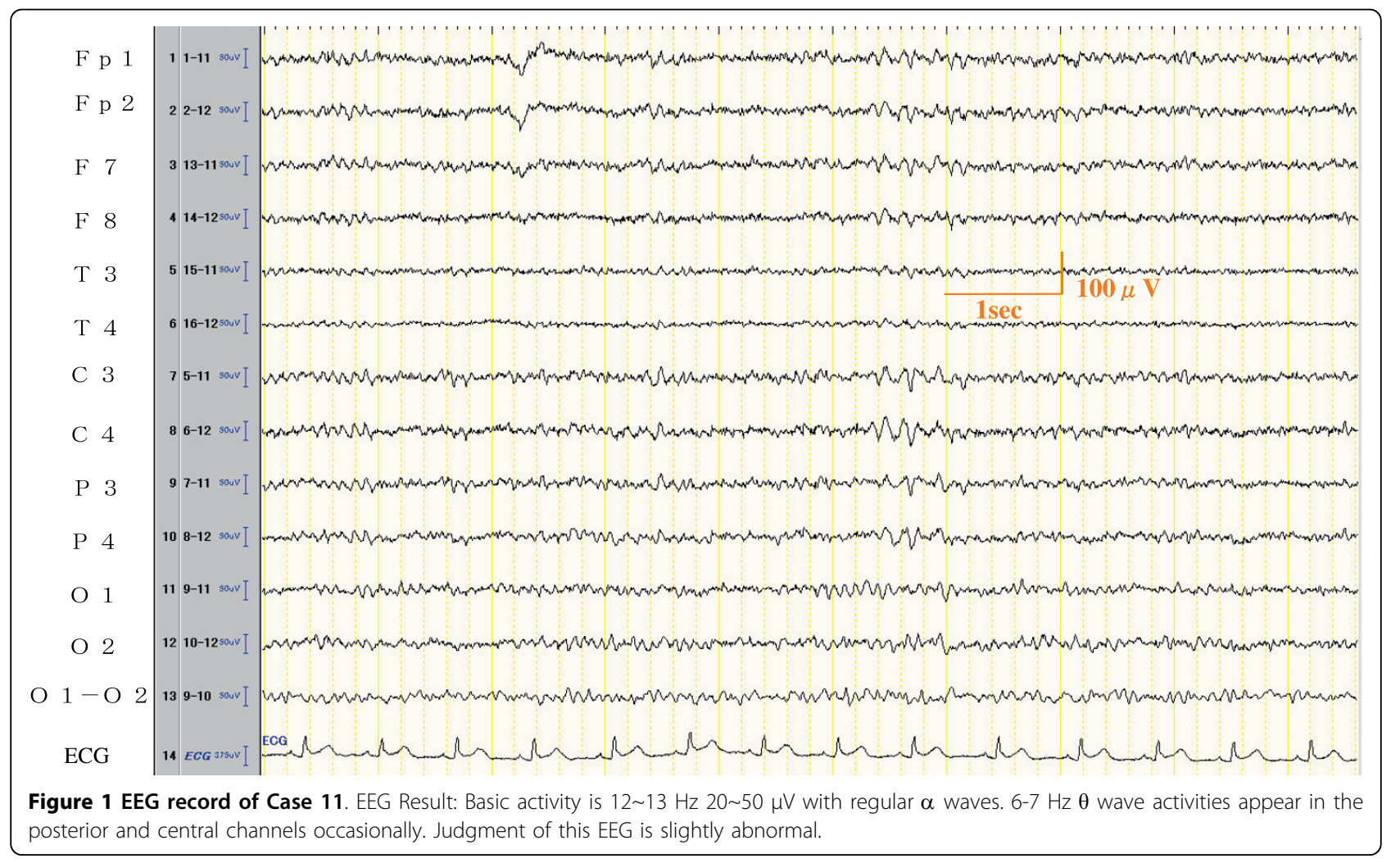




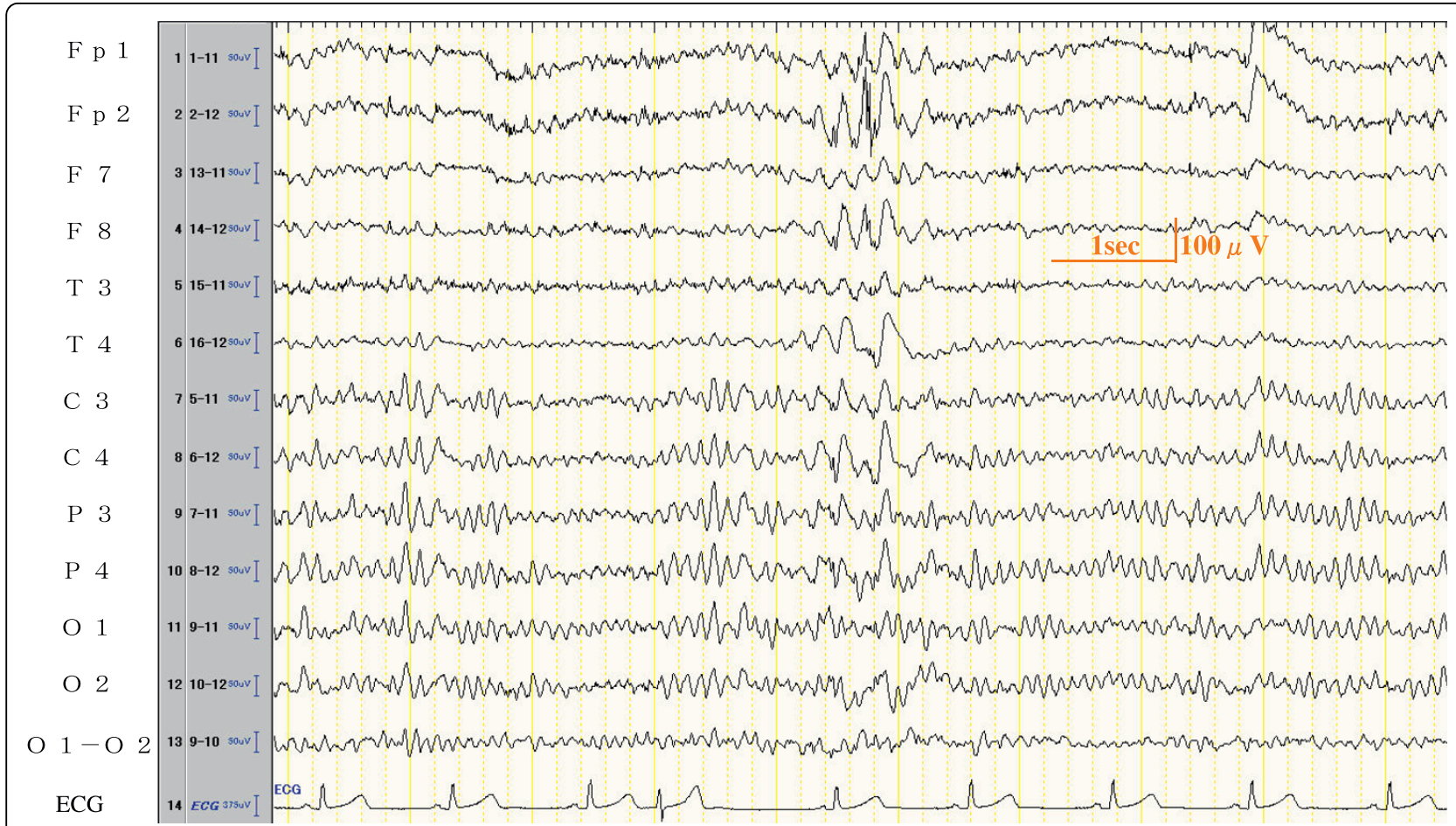

Figure 2 EEG record of Case 5. EEG Result: Basic activity is 10-11 Hz 30 100 $\mu \mathrm{V}$ with regular or irregular $\alpha$ waves. Sharp \& slow wave complexes appear in the right a few times. Judgment of this EEG is slightly abnormal.

number of panic patients in non-medicated condition and to compare the EEG with Computed Tomography (CT) results. In this study 13 patients, $24 \%$, displayed abnormal EEG recordings, and 6 patients, 20\%, exhibited abnormal CT scans [15].

The study of Dantendorfe et al. invited public participation of 120 subjects gathered through general practitioners and media. It was a case-control study in which
35 patients, $29.2 \%$ of the patients examined, showed EEG abnormalities. In this study, the panic disorder diagnosis was carried out by two independent psychiatrists and $40 \%$ of the subjects were under medication. EEGs were read by only one psychiatrist who had no relationship with the subjects [16].

The study of Bystrisky et al. was a part of the "Clinical trial examining the efficacy of clonazepam in the

Table 3 Comparison of 13 symptoms with the EEG findings of panic disorder patients

\begin{tabular}{ccc}
\hline & EEG normal patients = 53(\%) & EEG abnormal patients = 17(\%) \\
\hline palpitations, pounding heart, or accelerated heart rate & $44(83.0)$ & $13(76.5)$ \\
sweating & $11(20.8)$ & $5(29.4)$ \\
trembling or shaking & $16(30.2)$ & $5(29.4)$ \\
feeling of choking & $40(75.5)$ & $13(76.5)$ \\
sensations of shortness of breath or smothering & $13(24.5)$ & $4(23.5)$ \\
chest pain or discomfort & $22(41.5)$ & $7(41.2)$ \\
nausea or abdominal distress & $\mathbf{2 0 ( 3 7 . 7 )}$ & $\mathbf{1 4}(\mathbf{8 2 . 4 )}$ \\
feeling dizzy, unsteady, lightheaded, or faint & $38(71.7)$ & $15(88.2)$ \\
derealization or depersonalization & $\mathbf{4 ( 7 . 5 )}$ & $\mathbf{8}(\mathbf{4 7 . 1})$ \\
fear of losing control or going crazy & $23(43.4)$ & $11(64.7)$ \\
fear of dying & $16(30.2)$ & $5(29.4)$ \\
paresthesias & $\mathbf{2 3 ( 4 3 . 4 )}$ & $\mathbf{1 1}(\mathbf{6 4 . 7})$ \\
chills or hot flushes & $11(20.8)$ & $7(41.2)$ \\
\hline age & $34.6 \pm 9.3$ & $33.9 \pm 9.8$ \\
\hline
\end{tabular}


Table 4 EEG findings of panic disorder patients by the three factors extracted by multiple regression analysis

\begin{tabular}{|c|c|c|c|c|c|c|}
\hline & EEG normal patients $=53(\%)$ & EEG abnormal patients $=17(\%)$ & Wald & OR & $95 \% \mathrm{Cl}$ & $\mathbf{p}$ \\
\hline nausea or abdominal distress & $20(37.7)$ & $14(82.4)$ & 9.102 & 12.489 & $2.422-64.426$ & 0.003 \\
\hline derealization or depersonalization & $4(7.5)$ & $8(47.1)$ & 9.369 & 13.919 & $2.579-75.083$ & 0.002 \\
\hline paresthesias & $23(43.4)$ & $11(64.7)$ & 6.261 & 7.928 & $1.567-40.082$ & 0.012 \\
\hline
\end{tabular}

treatment of panic disorder" where patients use of psychotropic medication was strictly confirmed by blood and urine toxicology screens. 21 panic disorder patients together with 20 healthy volunteers participated in this case-control study. In this study, 5 patients, $23.8 \%$, showed EEG abnormalities. Patients with panic disorder in this study tended to have less alpha power in the right temporal region [17]. However, the EEGs were read by only one psychiatrist, without showing the decision criteria, and there were no double-checks.

Of the 70 cases with panic disorder who participated in this study, 17 patients, $24.3 \%$, were designated as abnormal in the final interpretation of EEG. The EEG abnormality rate reported for healthy people is in the range of 4.9-10\%[26-28]. Our findings also showed a high EEG abnormality rate among patients with panic disorder, although we had no control subjects.

\section{[Panic disorder and epilepsy]}

When considering the EEG abnormalities found in many panic disorder patients, epilepsy, the symptoms of which are similar to those of panic disorder, has to be carefully considered. In fact, comorbidity between panic disorder and epilepsy has been pointed out [23]. Recent studies associate epilepsy with an increased prevalence of anxiety disorder compared with the general population [29-31]. According to Tellez-Zenten, the lifetime prevalence of panic disorder in people with epilepsy was 6.6\%. In people without epilepsy it was 3.6\%[30]. Akanuma reported that $26.7 \%$ of idiopathic generalized epilepsy (IGE) patients were comorbid anxiety-panic disorder[31]. However we couldn't find the epidemiological evidence data of the prevalence of epilepsy in panic disorder populations. There are many reports about cases which had been initially diagnosed as panic disorder and later diagnosed as epilepsy[18,19], and the conclusion is that patients with panic disorder or epilepsy need to be examined in a careful way. There were some cases of repeated EEG and morphological tests (such as magnetic resonance imaging (MRI), CT, etc.), however we cannot tell panic disorder from epilepsy. For these patients, it is beneficial to consider EEG abnormalities in consecutive treatments [32]. According to Masnou, prescription of anticonvulsants is good, however, side effects and the condition of the patients needs to be observed carefully [19]. It should be mentioned that there were cases where panic disorder patients had been misdiagnosed with epilepsy and anticonvulsants had been prescribed for years[33,34].

There could be a risk that iatrogenic side effects may be caused in panic disorder and epilepsy. However, most of this literature is just case reports. Many of the actual EEG abnormality findings do not originate from epilepsy, although the EEG abnormality rate is high in panic disorder patients. Therefore, "epilepsy" is considered an important differential factor in the diagnosis of panic disorder; however, EEG abnormality cases are not always epilepsy.

\section{[EEG abnormal findings in panic disorder]}

All abnormal EEG findings were non-specific slow waves in Lepola and Dantendorfer's studies [15,16]. In the study of Stein, three of five were non-specific slow waves and two were paroxysmal abnormalities that could not be identified clearly as epileptiform discharges [14].

In the study of Bystritsk, there were 25\% EEG abnormal patients, and $15 \%$ of the patients had slow wave activity in the temporal regions with occasional bursts of sharp waves identified as epileptifom discharges. In addition, $10 \%$ of them had nonspecific increases in generalized slow wave activity [17]. Thus there is no consensus regarding EEG abnormality findings in panic disorder patients.

In our study, 13 cases had slow wave abnormalities which intermingled in intermittent slow activity and continuous slow activity, and only 2 of the 17 cases had paroxysmal abnormalities that were interpreted as epileptiform discharges. Daly and Bagchi et al. found in their EEG check that paroxysmal slow activity (similar slow wave burst) which were poor in locality reflected abnormalities in the brainstem or the deep brain near the brainstem, such as the thalamus, mesencephalon, medial frontal lobe, posterior cranial fossa, and thalamocele $[35,36]$. However, paroxysmal slow activities are sometimes found in widespread lesions over both the cerebral cortex and subcortical grey matter [37]. Also, in 1981 paroxysmal slow activity was considered to be a non-specific abnormality because it was difficult to infer the abnormal region [38].

\section{[EEG abnormalities in panic disorder]}

Based on the findings, it was considered that

i. Many panic disorder patients had EEG abnormalities. 
ii. It is important to make a differential diagnosis between panic disorder and epilepsy since they are intricately interrelated to each other and have clinical similarities. In this study, however, only two out of the 70 cases examined had epileptiform discharges. Accordingly, we could not confirm the rate of epilepsy cases to be high.

iii. The high rate of EEG abnormalities in panic disorder patients might have some relationship to physiological predispositions that easily cause panic attacks.

\section{[EEG abnormalities in panic disorder and the 13 symptoms]}

This is the first study that analyzed panic attack symptoms by dividing them into EEG normal and abnormal groups. In this study, 3 of the 13 symptoms, nausea or abdominal distress, derealization(feelings of unreality) or depersonalization (being detached from oneself), and paresthesias (numbness or tingling sensations) were extracted by multivariate analysis as factors related to EEG abnormalities in panic disorder.

In the past, Stein et al. could not find any relation between EEC abnormalities and psychosensory symptoms such as derealization, depersonalization, visual or auditory perceptual disturbances and forced thinking [14]. Weilburg et al. reported that they carried out EEG monitoring in 15 patients and found EEG changes during panic attacks, but could not extract any specific symptoms which might be related to EEG abnormalities [22]. Both Stein et al and Weilburg et al expected the existence of clinical symptoms related to EEG abnormalities and tried to investigate them in vain. Their efforts were not successful because number of subjects in their studies was small - 35 and 15 respectively -. In our study the number of subjects was 70, and the following three symptoms were extracted as factors related to EEG abnormalities.

\section{Nausea or abdominal distress}

One of the mechanisms of this symptom is the direct stimulations of the vomiting center in the medulla. EEG abnormality might be a factor to stimulate the vomiting center, though the relation between the abnormality and nausea cannot be established.

Gibbs \& Gibbs reported in 1967 that in cases with paroxysmal slow activities, the occurrence rate of nausea or vomiting is higher than that of a normal subject group [39]. Other than this one, we could not find any other references indicating the direct relationship between EEG abnormality and nausea or abdominal distress. In the gynecology field, it was reported that in pregnant women with hyperemesis gravidarum during the first trimester, the frequency of abnormal EEG findings is significantly higher compared to that in pregnant women with no nausea and vomiting symptoms during pregnancy. These findings were also nonspecific [40].
The EEG abnormality could be evidence that some abnormal changes have occurred in the brain. Subjects with EEG abnormality might be sensitive to nausea.

2. Derealization (feelings of unreality) or depersonalization (being detached from oneself)

Stein et al. proposed the relation of these psychosensory symptoms to EEG abnormalities. However they were not able to clarify significant differences in their study. We considered that significant results could be gotten due to the large number of cases in our study. Edlund reported that four of six patients with atypical panic attacks involving hostility, irritability, severe derealization, and social withdrawal had temporal EEG abnormalities that could not be clearly considered as epilepsy [41].

3. Paresthesias (numbness or tingling sensations)

We could not find any references indicating a direct relationship between EEG abnormality and this symptom. However Ietsugu et al. reported that "Paresthesia," could be good indicator of severe panic attacks [42]. According to Nishimura et al, panic disorder patients with first-degree familial history (FH) are significantly younger at onset, show more symptoms, and have more frequent attacks with paresthesias and chills or hot flashes at first panic attack compared to patients without first degree FH [43]. We think that EEG abnormalities in panic disorder patients might have some relation to physiological predispositions that easily cause panic attacks. Accordingly, paresthesia might be a symptom that suggests EEG abnormality.

\section{Study limitations}

Limitations in this study include the following:

1. There was a possibility that the EEG abnormality rate was high in the panic disorder patients in this study, although we can not determine this directly because of a lack of controls. Thus it will be necessary to reinvestigate comparing panic disorder patients and healthy people.

2. We grouped all EEG abnormality findings together and thus we can not refer to relationships between specific symptoms and specific EEG findings. Further studies with a larger number of subjects will be necessary to clarify our findings.

\section{Conclusion}

In this study, we surveyed EEG abnormalities in panic disorder patients. 17 of the 70 cases examined had EEG abnormalities. Most abnormal findings were slow wave bursts and slow waves. These abnormalities were nonspecific. Paroxysmal abnormality interpreted as epileptiform was found in only 2 of the 17 cases.

The following were extracted as factors related to EEG abnormalities in panic disorder: (i) nausea or abdominal 
distress, (ii) derealization (feelings of unreality) or depersonalization (being detached from oneself) and (iii) paresthesias (numbness or tingling sensations)

\section{Author details}

'Department of Neuropsychiatry, Sakura Medical Center, Faculty of Medicine, Toho University, Chiba, Japan. ${ }^{2}$ Department of Psychosomatic Medicine, Faculty of Medicine, Toho University, Tokyo, Japan. ${ }^{3}$ Support Center for Research and Education, Toho University, Tokyo, Japan.

\section{Authors' contributions}

MM carried out the revising the manuscript. MH carried out the statistical analysis and the revision of the manuscript. KN participated in the design of the study and the revision of the manuscript. KT carried out the revision of the manuscript. All authors read and approved the final manuscript

\section{Competing interests}

The authors declare that they have no competing interests.

Received: 29 January 2010 Accepted: 23 August 2010

Published: 23 August 2010

\section{References}

1. Katon W, Vitalianno PP, Russo J: Panic disorder: Epidemiology and primary care. J Fam Pract 1986, 23:233-239.

2. Markowitz JS, Weissmam MM, Ouelletter R, Lish JD, Klerman GL: Quality of life in panic disorder. Arch Gen Psychiatry 1989, 46:984-992.

3. Hwu HG, Yeh EK, Chang LY: Prevalence of psychiatric disorders in Taiwan defined by the Chinese diagnostic interview Schedule. Acta psychiatr Scand 1989, 79:136-147.

4. Eaton WW, Kessler RC, Wittchen HU, Magee WJ: Panic and Panic disorder in the United states. Am J Psychiatry 1994, 151:413-420.

5. Kaiya H, Umekage T, Harada S, Okazaki Y, Sasaki T: Factors associated with the development of panic attack and panic disorder: Survey in Japanese population. Psychiatry Clin Neurosci 2005, 59:177-182

6. Kaplan Harold I, Sadock Benjamin J: Panic disorder and Agoraphobia. Synopsis of Psychiatry Behavioral Sciences/Clinical Psychiatry Lippincott Williams \& Wilkins, 10 2007, 16.2:587-597.

7. Sakai Y, Kumano H, Nishikawa M, Sakano Y, Kaiya H, Imabayashi E Ohnishi T, Matsuda H, Yasuda A, Sato A, Diksic M, Kuboki T: Cerebral glucose metabolism associated with a fear network in panic disorder Neuroreport 2005, 16:972-931

8. Massana G, Serra-Grabulosa JM, Salgado-Pineda P, Gastó C, Junqué C, Massana J, Mercader JM, Gómez B, Tobeña A, Salamero M: Amygdalar atrophy in panic disorder patients detected by volumetric magnetic resonance imaging. Neurolmage 2003, 19:80-90

9. van den Heuvel OA, Veltman DJ, Groenewegen HJ, Witter MP, Merkelbach J, Cath DC, van Balkom AJ, van Oppen P, van Dyck R: DisorderSpecific Neuroanatomical Correlates of Attentional Bias in Obsessivecompulsive Disorder, Panic Disorder, and Hypochondriasis. Arch Gen Psychiatry 2005, 62:922-933.

10. Nishimura $Y$, Tanii H, Fukuda M, Kajiki N, Inoue K, Kaiya H, Nishida A, Okada M, Okazaki Y: Fronal dysfunction during a cognitive task in drugnaïve patients with panic disorder as investigated by multi-channel near-infrared spectroscopy imaging. Neurosci Res 2007, 59:107-112.

11. Weissman MM: Family genetic studies of panic disorder. J Psychiatr Res 1993, 27(suppl 1):69-78.

12. Skre I, Onstad S, Torgersen S, Lygren S, Kringlen E: A twin study of DSM- $\beta$ R anxiety disorders. Acta Psychiatr Scand 1993, 88:85-92.

13. Kendler KS, Neale MC, Kessler RC, Heath AC, Eaves LJ: Panic disorder in women: a population-based twin study. Psychological Medicine 1993, 23:397-406.

14. Stein MB, Unde TW: Infrequent occurrence of EEG abnormalities in panic disorder. Am J Psychiatry 1989, 146:517-520.

15. Lepola U, Nousiainen U, Puranen M, Riekkinen P, Rimon R: EEG and CT findings in patients with panic disorder. Biol Psychiatry 1990, 28:721-727.

16. Dantendorfer K, Prayer D, Kramer J, Amering M, Baischer W, Berger $P$, Schoder M, Steinberger K, Windhaber J, Imhof H, Katschnig H: High frequency of EEG and MRI brain abnormalities in panic disorder. Psychiatry Res 1996, 68:41-53.

17. Bystritsky A, Leuchter AF, Vapnik T: EEG abnormalities in nonmedicated panic disorder. J Nerv Ment Dis 1999, 187:113-114.

18. Saegusa S, Takahashi T, Moriya J, Yamakawa J, Itoh T, Kusaka K, Kawaura K Kanda T: Panic attack symptoms in a patient with left temporal lobe epilepsy. J Int Med Res 2004, 32:94-96.

19. Masnou P: True or pseudo epilepsy in the adult. Presse Med 2003, 32:420-425.

20. Nelson M, Prakash M, Jeffrey B: Panic Disorder and Complex Partial Seizures, A truly Complex relationship. Psychosomatics 1995, 36:498-502.

21. Vazquez B, Devinsky O: Epilepsy and Anxiety. Epilepsy \& Behavior 2003, 4:20-25.

22. Weilburg JB, Schachter S, Worth J, Pollack MH, Sachs GS, Ives JR, Schomer DL: EEG Abnormalities in Patients with Atypical Panic Attacks. J clin Psychiatry 1995, 56:358-362.

23. Langs $\mathrm{G}$, Fabisch $\mathrm{K}$, Fabisch $\mathrm{H}$ : A case of Comorbidity between Panic Disorder and Photosensitive Epilepsy. Psychopathology 2000, 33:271-274.

24. Niedermeyer E, Lopes da Silva F: Electroencephalography, Basic Principles, Clinical Applications, and Related fields Lippincot Williams \& Willkins, Phiradelphia, Fifth 2005.

25. Noachter S, Binnie C, Ebersole J, Mauguiere F, Sakamoto A, Westmoreland B: A glossary of terms most commonly used by clinical electroencephalographers and proposal for the report form for the EEG findings. Electroenceph clin Neurophysiol 1999, , Suppl 52: 21-41.

26. Gibbs F, Gibbs E, Lennox W: Electroencephalographic classification of epileptic patients and control subject. AMA Arch Neuropsychiatry 1943, 50:111-130.

27. Matousek M, Volavka J, Roubicek J, Roth Z: EEG frequency analysis related to age in normal adults. Electroencephalogr Clin Neurophysiol 1967, 23:162-167.

28. Eeg-Olofsson O: The development of the electroencephalogram in normal adolescents from the age of 16 through 21 years. Neuropadiatrie 1971, 3:11-45.

29. Lacey CJ, Salzberg MR, Roberts H, Trauer T, D'Souza WJ: Psychiatric comorbidity and impact on health service utilization in a community sample of patients with epilepsy. Epilepsia 2009, 50:1991-1994.

30. Tellez-Zenteno JF, Patten SB, Jetté N, Williams J, Wiebe S: Psychiatric comorbidity in epilepsy: a population-based analysis. Epilepsia 2007 48:2336-44.

31. Akanuma N, Hara E, Adachi N, Hara K, Koutroumanidis M: Psychiatric comorbidity in adult patients with idiopathic generalized epilepsy. Epilepsy Behav 2008, 13:248-51.

32. Gallinat J, Stotz-Ingenlath G, Lang U, Hegerl U: Panic attacks, spike-wave activity, and limbic dysfunction. A case report. Pharmacopsychiatry 2003, 36:123-126.

33. Pierre G, Fabrice B, Renzo G: Panic Attacks Mistaken for Relapse of Epilepsy. Epilepsia 1995, 36:48-51

34. Pegna C, Perri A, Lenti C: Panic disorder or temporal lobe epilepsy: A diagnostic problem in an adolescent girl. Eur Child Adolesc Psychiatry 1999, 8:237-239.

35. Daly D, Whelan JL, Bickford RG, Maccarty CS: The electroencephalogram in cases of tumors of the posterior fossa and third ventricle. Electroencephalogr Clin Neurophysiol 1953, 5:203-216.

36. Bagchi BK, Kooi KA, Selving BT: Subtentorial tumors and other letions: an electroencephalographic study of 121 cases. Electroencephalogr Clin Neurophysiol 1961, 13:180-192.

37. Gloor P, Kalabay O, Giard N: The electroencephalogram in diffuse encephalopathies: electroencephalographic correlates of grey and white matter lesions. Brain 1968, 91:779-802.

38. Schaul N, Gloor P, Gotman J: The EEG deep midline lesions. Neurology 1981, 31:157-167.

39. Gibbs F, Gibbs E: Paroxysmal Slow Actibity. Medical Electroencephalography Addison-Wesley Publishing Company Reading, Massachusetts 1967, 28-29.

40. Vaknin Z, Halperin R, Schneider D, Teitler J, Dar P, Herman A, Herman A, Berkovitch M: Hyperemesis gravidarum and nonspecific abnormal EEG findings: a preliminary report. J reprod Med 2006, 51:623-627.

41. Edlund MJ, Swann AC, Clothier J: Patients with panic attacks and abnormal EEG results. Am J Psychiatry 1987, 144:508-509. 
42. letsugu T, Sukigara M, Furukawa TA: Evaluation of diagnostic criteria for panic attack using item response theory: findings from the National Comorbidity Survey in USA. J Affect Disord 2007, 104:197-201.

43. Nishimura Y, Tanii H, Hara N, Inoue K, Nishida A, Okada M, Kaiya H, Okazaki Y: Specific panic attack symptoms in panic disorder patients with putative genetic factor. Psychiatry Clin Neurosci 2009, 63:251-252.

doi:10.1186/1751-0759-4-9

Cite this article as: Hayashi et al:: Electroencephalogram abnormalities in panic disorder patients: a study of symptom characteristics and pathology. BioPsychoSocial Medicine 2010 4:9.

Submit your next manuscript to BioMed Central and take full advantage of:

- Convenient online submission

- Thorough peer review

- No space constraints or color figure charges

- Immediate publication on acceptance

- Inclusion in PubMed, CAS, Scopus and Google Scholar

- Research which is freely available for redistribution

Submit your manuscript at www.biomedcentral.com/submit
C Biomed Central 